\title{
Article
}

\section{Improving the cost-effectiveness of photographic screening for diabetic macular oedema: a prospective, multi- centre, UK study}

Prescott, Gordon, Sharp, Peter, Goatman, Keith, Scotland, Graham, Fleming, Alan, Philip, Sam, Staff, Roger, Santiago, Cynthia, Borooah, Shyamanga, Broadbent, Deborah, Chong, Victor, Dodson, Paul, Harding, Simon, Leese, Graham, Megaw, Roly, Styles, Caroline, Swa, Ken, Wharton, Helen and Olson, John

Available at https://clok.uclan.ac.uk/25109/

Prescott, Gordon orcid iconORCID: 0000-0002-9156-2361, Sharp, Peter, Goatman, Keith, Scotland, Graham, Fleming, Alan, Philip, Sam, Staff, Roger, Santiago, Cynthia, Borooah, Shyamanga et al (2014) Improving the costeffectiveness of photographic screening for diabetic macular oedema: a prospective, multi-centre, UK study. British Journal of Ophthalmology, 98 (8). pp. 1042-1049. ISSN 0007-1161

It is advisable to refer to the publisher's version if you intend to cite from the work. http://dx.doi.org/10.1136/bjophthalmol-2013-304338

For more information about UCLan's research in this area go to

http://www.uclan.ac.uk/researchgroups/ and search for <name of research Group>.

For information about Research generally at UCLan please go to http://www.uclan.ac.uk/research/

All outputs in CLoK are protected by Intellectual Property Rights law, including Copyright law. Copyright, IPR and Moral Rights for the works on this site are retained by the individual authors and/or other copyright owners. Terms and conditions for use of this material are defined in the policies page. 
Improving the Cost-Effectiveness of Photographic Screening for Diabetic Macular Oedema: A Prospective, Multi-Centre, United Kingdom Study

Author list:

Gordon Prescott1, Peter Sharp2, Keith Goatman2, Graham Scotland1, Alan Fleming2, Sam Philip3, Roger Staff4, Cynthia Santiago5, Shyamanga Borooah6, Deborah Broadbent7,8, Victor Chong9, Paul Dodson10, Simon Harding7,8, Graham Leese11, Roly Megaw6, Caroline Styles12, Ken Swa13, Helen Wharton14, John Olson15*

Institutions:

1 School of Medicine \& Dentistry, Division of Applied Health Sciences, Foresterhill, Aberdeen, 2 College of Life Sciences and Medicine, University of Aberdeen, Foresterhill, Aberdeen, 3 Grampian Diabetes Research Unit Diabetes Centre, Woolmanhill Hospital, Aberdeen, 4 Medical Physics, NHS Grampian, Aberdeen, 5 Eye Out-patient Department, Aberdeen Royal Infirmary, 6 Princess Alexandra Eye Pavilion, Edinburgh, 7 Liverpool Diabetes Eye Centre, St. Paul's Eye Unit, Royal Liverpool University Hospital, Liverpool, 8 Department of Eye and Vision Science, Institute of Ageing and Chronic Disease, University of Liverpool, Daulby Street, Liverpool, 9 Oxford Eye Hospital, Oxford, 10 Heartlands Hospital \& Aston University, 11 Ninewells Hospital, Dundee, 12 Queen Margaret Hospital, Dunfermline, 13 National Services Scotland, Edinburgh, 14 Birmingham and Black Country Diabetic Eye Screening Programme, Diabetes and Endocrinology Unit, Heartlands Hospital, Bordesley Green, Birmingham, 15 Grampian Retinal Screening Programme, David Anderson Building, Aberdeen.

*Corresponding author

Dr John Olson

Clinical Director

Grampian Retinal Screening Programme

David Anderson Building

Foresterhill Road

Aberdeen

AB25 2ZP

john.olson@nhs.net 
01224550466

Key words/Mesh headings:

Retina, Macula, Diagnostic Tests/Investigation

Word count: 2488 


\section{ABSTRACT}

Background/aims

Retinal screening programmes in England and Scotland have similar photographic grading schemes for background (non-proliferative) and proliferative diabetic retinopathy, but diverge over maculopathy. We looked for the most cost-effective method of identifying diabetic macular oedema from retinal photographs; including the role of automated grading and optical coherence tomography, a technology that directly visualises oedema. Methods

Patients from seven UK centres were recruited. The following features in at least one eye were required for enrolment: microaneurysms/dot haemorrhages or blot haemorrhages within one disc diameter, exudates within one or two disc diameters of the centre of the macula. Subjects had optical coherence tomography and digital photography. Manual and automated grading schemes were evaluated. Costs and QALYs were modelled using microsimulation techniques.

Results

3540 patients were recruited, 3170 were analysed. For diabetic macular oedema, England's scheme had a sensitivity of $72.6 \%$ and specificity of $66.8 \%$; Scotland's a sensitivity of $59.5 \%$ and specificity of $79.0 \%$. When applying a ceiling ratio of $£ 30,000$ per QALY gained, Scotland's scheme was preferred. Assuming automated grading could be implemented without increasing grading costs, automation produced a greater number of QALYS for a lower cost than England's scheme, but was not cost effective, at the study's operating point, compared to Scotland's. The addition of optical coherence tomography, to each scheme, resulted in cost savings without reducing health benefits.

Conclusion

Retinal screening programmes in the United Kingdom should reconsider the screening pathway to make best use of existing and new technologies. 


\section{INTRODUCTION}

Diabetic retinal screening programmes in the United Kingdom differ over how surrogate photographic markers are used to screen patients for diabetic macular oedema. England utilises exudates within two disc diameters of the centre of the macula and, if visual acuity is reduced, blot haemorrhages and microaneurysms/dot haemorrhages within one disc diameter. Scotland only utilises exudates and blot haemorrhages within one disc diameter, regardless of the visual acuity.

We investigated the accuracy and cost-effectiveness of these schemes using optical coherence tomography (OCT), a technology that directly visualises oedema, as the reference standard. Additionally we investigated the accuracy and cost-effectiveness of automated grading and the role of OCT in screening for diabetic macular oedema.[1-3]

\section{MATERIALS AND METHODS}

This was a multi-centre, prospective, observational cohort study. Participants with diabetes were recruited from retinopathy screening and ophthalmology in Aberdeen, Birmingham, Dundee, Dunfermline, Edinburgh, Liverpool and Oxford. Patients aged 18 or older who gave informed consent were included. The following photographic features in at least one eye were required for recruitment: microaneurysms/dot haemorrhages or blot haemorrhages within one disc diameter, exudates within one or two disc diameters of the centre of the macula. Exclusions were: pregnancy; contra-indications to dilatation; intraocular surgery within one year; macular or pan-retinal laser treatment; or intraocular injection. The reference standard was an adequate OCT image of both eyes. Patients were omitted from analysis if they had an inadequate OCT image in either eye. Patients with an adequate retinal photograph in one eye were included.

To avoid inter-centre variation, OCT operators submitted a portfolio of images for accreditation.

A $45^{\circ}$ macula-centred colour digital retinal photograph (3-8 megapixels, with or without JPEG compression) was obtained from each eye. OCT images were obtained from each eye producing a nine subfield "Early Treatment of Diabetic 
Retinopathy Study" (ETDRS) map showing average regional thickness, and a horizontal cross-section through the centre of the macula or the region of greatest thickness. [4] The outer four regions were disregarded. Best logMAR visual acuity was recorded unaided, with pinhole or with glasses. There was a maximum of 4 weeks between photograph and OCT scan.

All images were graded and annotated by a quality assured grader ( $94.3 \%$ sensitivity, 95.7\% specificity, for referable retinopathy/maculopathy, 2012[5]) prior to reviewing the OCT data Borderline images were referred to a senior ophthalmologist.

Diabetic macular oedema was deemed present if:

- Central ETDRS region thickness $>250 \mu \mathrm{m}$ or any of inner five regions $>300 \mu \mathrm{m}$;

- AND visible intra-retinal cyst or area of sub-retinal fluid on OCT crosssection;

- AND no other visible cause for macular oedema e.g. vein occlusion.

Thickness thresholds were adjusted to account for all scanners used in the study.[3]

\section{Grading Schemes}

England's, Scotland's and a hybrid scheme, utilising features from both, were assessed (Table 1).

A fully automated grading scheme was developed utilising existing software. $[6,7]$ Automated inputs included: image feature intensity; image clarity; counts of microaneurysms/dot haemorrhages within one disc diameter and two disc diameters; likelihoods of haemorrhages within one disc diameter and anywhere in the image; likelihoods of exudates within one disc diameter, two disc diameters and anywhere in the image; and visual acuity. 
TABLE 1 Referral criteria for manual grading strategies.

\begin{tabular}{|c|c|c|c|c|}
\hline $\begin{array}{l}\text { Criteria for } \\
\text { referral to } \\
\text { Ophthalmology }\end{array}$ & $\begin{array}{l}\text { Micro- } \\
\text { aneurysm/dot } \\
\text { haem }^{\mathrm{a}} \\
\text { within } 1 \text { DD }\end{array}$ & $\begin{array}{l}\text { Blot haem. } \\
\text { within } 1 \text { DD }\end{array}$ & $\begin{array}{l}\text { Exudate } \\
\text { within } 1 \text { DD }\end{array}$ & $\begin{array}{l}\text { Exudate } \\
\text { within 1-2 DD } \\
\text { (if not in } 1 \\
\text { DD) }\end{array}$ \\
\hline England & $\begin{array}{l}\text { Only if } \\
\text { logMAR VA } \\
0.3 \text { or worse }\end{array}$ & $\begin{array}{l}\text { Only if } \\
\text { logMAR VA } \\
0.3 \text { or worse }\end{array}$ & Yes & Yes \\
\hline Scotland & No & Yes & Yes & No \\
\hline Hybrid & $\begin{array}{l}\text { Only if } \\
\text { logMAR VA } \\
0.3 \text { or worse }\end{array}$ & Yes & Yes & No \\
\hline
\end{tabular}

${ }^{a}$ haem $=$ haemorrhage/s 
Patients with inadequate quality photographs, but no referable disease, were sent for slit-lamp examination, reflecting clinical practice. For automated grading, it was assumed that patients assigned the outcome of inadequate quality photographs would be referred for manual grading (hybrid grading scheme), and then to slit-lamp, if manual grading concurred.

To identify sampling bias, patients were classified into a hierarchy of five mutually exclusive categories of features present in either eye:

1. Exudates within one disc diameter.

2. Blot haemorrhages, but no exudates, within one disc diameter.

3. Microaneurysms/dot haemorrhages, but no exudates or blots, within one disc diameter.

4. Exudates within one -two disc diameters with no relevant diabetic retinopathy features within one disc diameter.

5. None of the above.

Weighting was undertaken to correct for sampling bias, based on observed proportions of the above categories in a consecutive cohort of 6,900 patients attending retinal screening in Grampian.[8,9] Each weight[10-12] was calculated as the ratio of the observed proportion in the cohort study[9] to that in the present study.

For both weighted and unweighted data, the sensitivity and specificity of using each investigated scheme were estimated at the patient level.[13] For these calculations, referral of the patient corresponded to a scheme applied to both eyes separately indicating referral in either eye (or both).

\section{Cost Effectiveness Analysis}

A Markov microsimulation model was developed to assess the cost-effectiveness of the alternative grading schemes for triggering referral in the context of annual screening, with and without OCT prior to referral. A time horizon of 20 years was adopted. Based on epidemiological and clinical effectiveness data, the model simulated the progression of macular oedema and visual loss in each eye of referred and un-referred patients. The model assumed that patients with 
macular oedema would receive laser treatment, whilst those not referred would be screened one year later.[14,15] An alternative scenario was modelled whereby only those with macular oedema and visual acuity $\geq 0.3 \log M a r$ received laser. Health care costs associated with photographic screening ( $£ 46.69$ per patient), the addition of OCT to the screening pathway ( $£ 31.96$ per patient), initial referral ( $£ 143 \cdot 35)$, treatment ( $£ 160$ per treatment per eye), on-going monitoring ( $£ 117$ per visit)) were estimated from a resource use questionnaire sent to participating centres and other published sources.[16,17] Health and social care costs of severe vision loss $(£ 6,295$ per year) were taken from a previous study.[18] See web appendix.

The analysis simulated the passage of 100,000 "patients", with characteristics matching those of patients in the clinical dataset, through the model individually. As above, the proportions of patients in the different feature categories were weighted. The impact of using alternative grading schemes within annual screening was assessed by applying the weighted sensitivities and specificities within the model. Modelling was also used to assess the cost per case of macular oedema detected from one round of screening for this cohort (see appendix).

The mean costs, years free of moderate visual loss (in either eye) and quality adjusted life years accruing to patients, under the alternative grading schemes, were compared to estimate incremental cost-effectiveness ratios (ICERs). The schemes were compared both with and without the use of OCT prior to referral. We also assessed a scheme (Scheme A) whereby anyone with markers of diabetic maculopathy would be examined with OCT. A ceiling willingness to pay ratio of $£ 30,000$ per QALY gained was applied to identify the optimal scheme on grounds of cost-effectiveness.[19]

To characterise the uncertainty surrounding the cost-effectiveness of alternatives, deterministic and probabilistic sensitivity analyses were undertaken. The probabilistic analysis sampled from distributions assigned to each model parameter, and simulated the passage of 10,000 patients through the model 1000 times. This produced 1000 estimates of the mean cost and effects for each scheme. Cost-effectiveness acceptability curves were produced by calculating the proportion of these iterations favouring each of the schemes (on grounds of cost-effectiveness) at different ceiling ratios of willingness to pay 
per QALY.[20] The methods used to derive probabilities for visual loss and the development of macular oedema precluded determination of the statistical impression surrounding these estimates. The impact of variation in these parameters was addressed through deterministic sensitivity analysis.

\section{RESULTS}

3540 patients were recruited between 31/07/2008 and 22/02/2011 (Figure 1). 370 were excluded from analysis: in 329 the OCT failed in at least one eye; in a further 41 retinal photographs from both eyes were of inadequate quality; and there was 1 lost image (Figure 2).

3170 patients were analysed (Table 2) of which 243 (7.7\%) had diabetic macular oedema. Prevalence of diabetic macular oedema differed between centres (range $3 \cdot 7 \%$ to $12 \cdot 2 \%$ ) and scanners (range $4 \cdot 5 \%$ to $11 \cdot 8 \%$ ). Diabetic macular oedema was statistically commoner in older people, Caucasians, those with type 2 diabetes or poor visual acuity.

When mutually exclusive categories of lesions were considered, diabetic macular oedema was present in $14.1 \%$ of those with exudates within one disc diameter; $12 \cdot 1 \%$ of those with blot haemorrhages (but no exudates within one disc diameter); and $3 \cdot 2 \%$ of those with microaneurysms/dot haemorrhages (and no exudates or blot haemorrhages within one disc diameter) (Table 2).

Table 3 shows the analysis weights used to correct for sampling bias. Exudates within one disc diameter and blot haemorrhages were down weighted. Exudates between one and two disc diameters and microaneurysms/dot haemorrhages were up weighted.

Table 4 shows the sensitivities and specificities for predicting the presence of diabetic macular oedema from certain lesion combinations for unweighted and weighted data. The presence of exudates within one disc diameter had the greatest influence on the prediction of macular oedema. The addition of exudates between one -two disc diameters did not identify any further cases (Table 4). 
TABLE 2 Demographics by optical coherence tomography macular oedema status

\begin{tabular}{|c|c|c|c|c|c|c|c|}
\hline & $\begin{array}{l}\text { Total } \\
\text { n }\end{array}$ & $\%$ & $\begin{array}{l}\text { Oedema } \\
\text { present } \\
\text { (At } \\
\text { least } \\
\text { one } \\
\text { eye) n }\end{array}$ & & $\begin{array}{l}\text { Oedema } \\
\text { absent } \\
\text { (Both } \\
\text { eyes) n }\end{array}$ & $\%$ & $\begin{array}{l}\text { p-value } \\
\text { (oedema } \\
\text { present } \\
\text { vs. } \\
\text { absent) }\end{array}$ \\
\hline Number of cases & 3170 & & 243 & & 2927 & & \\
\hline $\begin{array}{l}\text { Age tmedian } \\
\text { (interquartile } \\
\text { range) }\end{array}$ & $60+$ & $\begin{array}{l}(49, \\
69)\end{array}$ & $67+$ & $\begin{array}{l}(58, \\
75)\end{array}$ & $59+$ & $\begin{array}{l}(48, \\
69)\end{array}$ & $<0.001$ \\
\hline Sex (male) & 1925 & $60 \cdot 7$ & 147 & $60 \cdot 5$ & 1778 & $60 \cdot 7$ & 0.993 \\
\hline Ethnicity & & & & & & & 0.015 \\
\hline Caucasian & 2678 & $84 \cdot 5$ & 223 & $91 \cdot 8$ & 2455 & $84 \cdot 5$ & \\
\hline Asian & 369 & $11 \cdot 6$ & 16 & $6 \cdot 6$ & 353 & $12 \cdot 1$ & \\
\hline Black & 74 & $2 \cdot 3$ & 2 & 0.8 & 72 & $2 \cdot 5$ & \\
\hline Other/Unknown & 49 & $1 \cdot 5$ & 2 & 0.8 & 47 & $1 \cdot 6$ & \\
\hline Diabetes: & & & & & & & $<0.001^{*}$ \\
\hline Type 1 & 709 & $22 \cdot 4$ & 28 & $11 \cdot 5$ & 681 & $23 \cdot 3$ & \\
\hline Type 2 & 2452 & $77 \cdot 4$ & 213 & $87 \cdot 7$ & 2239 & $76 \cdot 5$ & \\
\hline Unspecified & 4 & $0 \cdot 1$ & 2 & $0 \cdot 8$ & 2 & $0 \cdot 1$ & \\
\hline Unknown & 5 & $0 \cdot 2$ & 0 & 0.0 & 5 & 0.2 & \\
\hline Glitazone use (yes) & 177 & $5 \cdot 6$ & 10 & $4 \cdot 1$ & 167 & $5 \cdot 7$ & 0.372 \\
\hline Amblyopia (either & 86 & $2 \cdot 7$ & 83 & $2 \cdot 8$ & 3 & $1 \cdot 2$ & 0.204 \\
\hline
\end{tabular}




\begin{tabular}{|c|c|c|c|c|c|c|c|}
\hline & $\begin{array}{l}\text { Total } \\
\text { n }\end{array}$ & $\%$ & $\begin{array}{l}\text { Oedema } \\
\text { present } \\
\text { (At } \\
\text { least } \\
\text { one } \\
\text { eye) n }\end{array}$ & & $\begin{array}{l}\text { Oedema } \\
\text { absent } \\
\text { (Both } \\
\text { eyes) } n\end{array}$ & $\%$ & $\begin{array}{l}\text { p-value } \\
\text { (oedema } \\
\text { present } \\
\text { vs. } \\
\text { absent) }\end{array}$ \\
\hline $\begin{array}{l}\text { yes) } \\
\text { Visual acuity (Left } \\
\text { eye) } \neq\end{array}$ & & & & & & & $<0.001$ \\
\hline $\begin{array}{l}\text { Better } \\
(\log M A R<0 \cdot 3)\end{array}$ & 2807 & $88 \cdot 5$ & 163 & $67 \cdot 1$ & 2644 & $90 \cdot 3$ & \\
\hline $\begin{array}{l}\text { Worse } \\
(\log M A R \geq 0 \cdot 3)\end{array}$ & 348 & $11 \cdot 0$ & 77 & $31 \cdot 7$ & 271 & $9 \cdot 3$ & \\
\hline $\begin{array}{l}\text { Missing } \\
\text { Visual acuity } \neq \\
\text { (Right eye) }\end{array}$ & 15 & $0 \cdot 5$ & 3 & $1 \cdot 2$ & 12 & $0 \cdot 4$ & $<0.001$ \\
\hline $\begin{array}{l}\text { Better } \\
(\log M A R<0 \cdot 3)\end{array}$ & 2794 & $88 \cdot 1$ & 164 & $67 \cdot 5$ & 2630 & 89.9 & \\
\hline $\begin{array}{l}\text { Worse } \\
(\log M A R \geq 0 \cdot 3)\end{array}$ & 361 & $11 \cdot 4$ & 74 & $30 \cdot 5$ & 287 & $9 \cdot 8$ & \\
\hline Missing & 15 & $0 \cdot 5$ & 5 & $2 \cdot 1$ & 10 & $0 \cdot 3$ & \\
\hline $\begin{array}{l}\text { Mutually exclusive } \\
\text { categories }\end{array}$ & & & & & & & $<0.001$ \\
\hline Exudates < 1 DD & 1024 & $32 \cdot 3$ & 144 & $59 \cdot 3$ & 880 & $30 \cdot 1$ & \\
\hline $\begin{array}{l}\text { Blots (no exudates) } \\
<1 \text { DD }\end{array}$ & 423 & $13 \cdot 3$ & 51 & $21 \cdot 0$ & 372 & $12 \cdot 7$ & \\
\hline Microaneurysms & 1371 & $43 \cdot 2$ & 44 & $18 \cdot 1$ & 1327 & $45 \cdot 3$ & \\
\hline
\end{tabular}




\begin{tabular}{|c|c|c|c|c|c|c|c|}
\hline & $\begin{array}{l}\text { Total } \\
\text { n }\end{array}$ & $\%$ & $\begin{array}{l}\text { Oedema } \\
\text { present } \\
\text { (At } \\
\text { least } \\
\text { one } \\
\text { eye) } n\end{array}$ & $\%$ & $\begin{array}{l}\text { Oedema } \\
\text { absent } \\
\text { (Both } \\
\text { eyes) n }\end{array}$ & $\%$ & $\begin{array}{l}\text { p-value } \\
\text { (oedema } \\
\text { present } \\
\text { vs. } \\
\text { absent) }\end{array}$ \\
\hline only $<1$ DD & & & & & & & \\
\hline Exudates 1-2 DD & 27 & 0.9 & 0 & $0 \cdot 0$ & 27 & 0.9 & \\
\hline $\begin{array}{l}\text { No relevant diabetic } \\
\text { retinopathy } \\
\text { features }<2 D D\end{array}$ & 325 & $10 \cdot 3$ & 4 & $1 \cdot 6$ & 321 & $11 \cdot 0$ & \\
\hline
\end{tabular}

DD disc diameter radius

*Comparison of 3 categories of diabetes (type 1, type 2 and other) as unknown and unspecified combined for statistical test.

\#Visual acuity better (logMAR<0.3, Snellen $6 / 9 \cdot 5$ or better) and visual acuity worse (logMAR $\geq 0 \cdot 3$, Snellen $6 / 12$ or worse) 
TABLE 3 Patient category proportions used in the statistical and costeffectiveness analyses

\begin{tabular}{|c|c|c|c|}
\hline Category & $\begin{array}{l}\text { Proportion in } \\
\text { earlier study }\end{array}$ & $\begin{array}{l}\text { Number } \\
\text { in current } \\
\text { study }\end{array}$ & $\begin{array}{l}\text { Weights for } \\
\text { weighted } \\
\text { analysis }\end{array}$ \\
\hline Exudate(s) within 1 DD & $\begin{array}{l}203 / 1099= \\
0 \cdot 185\end{array}$ & 1024 & 0.572 \\
\hline $\begin{array}{l}\text { blot haemorrhage(s) (no } \\
\text { exudates) within } 1 \text { DD }\end{array}$ & $\begin{array}{l}50 / 1099= \\
0.045\end{array}$ & 423 & 0.341 \\
\hline $\begin{array}{l}\text { Microaneurysm(s)/dot } \\
\text { haemorrhage(s) (no } \\
\text { blots) within } 1 \text { DD }\end{array}$ & $\begin{array}{l}829 / 1099= \\
0.754\end{array}$ & 1371 & $1 \cdot 744$ \\
\hline $\begin{array}{l}\text { Exudate(s) between } 1 \& \\
2 \text { DD }\end{array}$ & $\begin{array}{l}17 / 1099= \\
0.015\end{array}$ & 27 & $1 \cdot 816$ \\
\hline $\begin{array}{l}\text { No relevant DR features } \\
\text { within macula }\end{array}$ & & 325 & 0 \\
\hline Excluded & & 370 & 0 \\
\hline
\end{tabular}

DD disc diameter 
TABLE 4 Sensitivity and specificity for the manually identified lesions

\begin{tabular}{|c|c|c|c|c|c|c|c|c|c|c|c|c|}
\hline & \multicolumn{6}{|c|}{ Unweighted } & \multicolumn{6}{|c|}{ Weighted } \\
\hline & \multicolumn{6}{|c|}{$\begin{array}{l}\mathrm{N}=3170 \\
\text { Macular Oedema } \mathrm{N}=243\end{array}$} & \multicolumn{6}{|c|}{$\begin{array}{l}\mathrm{N}=3170 \\
\text { Macular Oedema } \mathrm{N}=176\end{array}$} \\
\hline $\begin{array}{l}\text { Lesion within } 1 \\
\text { DD }\end{array}$ & $\begin{array}{l}\mathrm{MO} \\
\mathrm{N}\end{array}$ & $\begin{array}{l}\text { Not } \\
\text { MO } \\
\text { N }\end{array}$ & $\begin{array}{l}\text { Sens } \\
\%\end{array}$ & $\begin{array}{l}\text { Spec } \\
\%\end{array}$ & $\begin{array}{l}\text { PPV } \\
\%\end{array}$ & $\begin{array}{l}\text { NPV } \\
\%\end{array}$ & $\begin{array}{l}\mathrm{MO} \\
\mathrm{N} *\end{array}$ & $\begin{array}{l}\text { Not } \\
\text { MO } \\
\text { N* }\end{array}$ & $\begin{array}{l}\text { Sens } \\
\%\end{array}$ & $\begin{array}{l}\text { Spec } \\
\%\end{array}$ & $\begin{array}{l}\text { PPV } \\
\%\end{array}$ & $\begin{array}{l}\text { NPV } \\
\%\end{array}$ \\
\hline MA only & 44 & 1327 & $18 \cdot 1$ & $54 \cdot 7$ & $3 \cdot 2$ & 88.9 & 77 & 2314 & $43 \cdot 8$ & $22 \cdot 7$ & $3 \cdot 2$ & $87 \cdot 3$ \\
\hline $\begin{array}{l}\text { MA or blots (no } \\
\text { exudates) }\end{array}$ & $95+$ & 1699 & $39 \cdot 1$ & $42 \cdot 0$ & $5 \cdot 3$ & $89 \cdot 2$ & 94 & 2441 & $53 \cdot 4$ & $18 \cdot 4$ & $3 \cdot 7$ & $87 \cdot 1$ \\
\hline $\begin{array}{l}\text { MA or blots or } \\
\text { exudates }\end{array}$ & 239 & 2579 & $98 \cdot 4$ & $11 \cdot 9$ & $8 \cdot 5$ & $98 \cdot 9$ & 176 & 2944 & $100 \cdot 0$ & $1 \cdot 7$ & $5 \cdot 6$ & $100 \cdot 0$ \\
\hline $\begin{array}{l}\text { MA or blots or } \\
\text { exudates or } \\
\text { exudates } 1-2 \\
\text { DD }\end{array}$ & 239 & 2606 & $98 \cdot 4$ & $11 \cdot 0$ & $8 \cdot 4$ & $98 \cdot 8$ & 176 & 2993 & $100 \cdot 0$ & 0.0 & $5 \cdot 6$ & N/A \\
\hline
\end{tabular}

*Counts in the weighted analysis are rounded to the nearest whole number 
TThe numbers presented are cumulative. There are 95 with MA or blots ( 44 with MA only and 51 with blots or both MA and blots) 
England's scheme, after weighting, had sensitivity of $72.6 \%$ and specificity of $66.8 \%$ for detection of diabetic macular oedema; Scotland's sensitivity of $59 \cdot 5 \%$ and specificity of $79 \%$. The hybrid scheme had sensitivity of $73.3 \%$ and specificity of $70 \cdot 9 \%$ (Table 5 ).

The receiver operating characteristic curve for automated grading is shown in Figure 3 together with the sensitivities and specificities for the three manual schemes. Compared to the manual schemes, for the same sensitivity, automated grading achieved a higher specificity. The automated system operating point used in the cost-effectiveness analysis had slightly higher sensitivity (75.9\%) and specificity $(73 \cdot 7 \%)$ than the hybrid manual grading scheme (Table 5 ).

The results of the short term analysis of the cost per case detected from one round of screening are presented in the web appendix.

Table 6 shows the results of the cost-effectiveness analysis. The addition of OCT to each scheme resulted in cost-savings without reducing health benefits. Scotland's scheme was found to be most cost-effective at the accepted ceiling ratio of $£ 30,000$ per QALY, with or without the addition of OCT. Even scheme $A$, where any one with markers of diabetic maculopathy is examined with OCT, produces cost savings over all the manual schemes without OCT.

In the study, automated grading had higher specificity but similar sensitivity to England's and the hybrid scheme (Figure 3). Assuming that automated grading was implemented for a similar cost to manual grading, it has the potential to produce a similar number of QALYs, but at a lower overall cost to the health service, than either England's or the hybrid scheme. Automated grading could be made cost-effective in Scotland, but an operating point at a higher specificity would have to be chosen.

Deterministic sensitivity analysis suggested that monitoring patients with suspected diabetic macular oedema (on a 6-monthly basis) with OCT and retinal photography remained cost saving up to an incremental cost of $\sim £ 58$ per patient. Further scenario analyses assessed the sensitivity of findings to alterations in assumptions and parameters in favour of the more sensitive and less specific strategies (see web appendix). Only when a number of parameters were simultaneously weighted in favour of the more sensitive strategies, did 
incremental cost per QALY approach the accepted threshold range (£20-30,000 per QALY). 
TABLE 5 Sensitivity and specificity for the various manual grading schemes and for the operating point chosen for automated grading scheme.

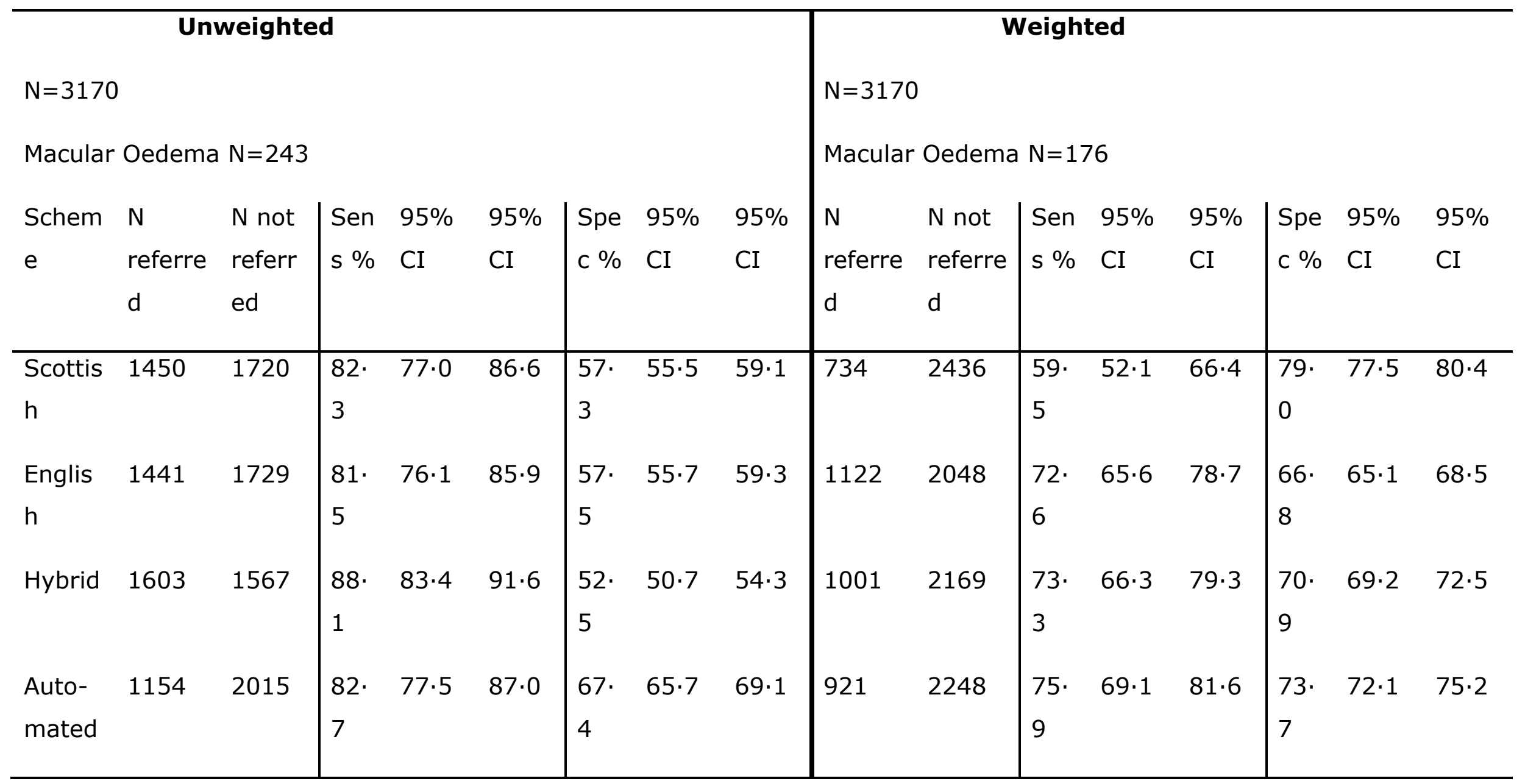


TABLE 6 Expected costs, years free from moderate visual loss and quality adjusted life years per patient over a twenty year period using alternative screening strategies (based on a simulated cohort of 100,000 patients with macular pathology)

\begin{tabular}{|c|c|c|c|c|c|c|c|c|c|}
\hline Scheme & $\begin{array}{l}\text { Total } \\
\text { cost } \\
\text { (mean } \\
\text { ) }\end{array}$ & $\begin{array}{l}\text { Increment } \\
\text { al cost }\end{array}$ & $\begin{array}{l}\text { Years } \\
\text { free from } \\
\text { moderate } \\
\text { visual } \\
\text { loss } \\
\text { (mean) }\end{array}$ & $\begin{array}{l}\text { Incremental } \\
\text { years free } \\
\text { from } \\
\text { moderate } \\
\text { visual loss }\end{array}$ & $\begin{array}{l}\text { Incremental } \\
\text { cost per } \\
\text { year free of } \\
\text { moderate } \\
\text { visual loss }\end{array}$ & $\begin{array}{l}\text { quality } \\
\text { adjusted } \\
\text { life } \\
\text { years } \\
\text { (mean) }\end{array}$ & $\begin{array}{l}\text { Incremental } \\
\text { quality } \\
\text { adjusted } \\
\text { life years }\end{array}$ & $\begin{array}{l}\text { Incremental } \\
\text { cost per } \\
\text { quality } \\
\text { adjusted } \\
\text { life year }\end{array}$ & $\begin{array}{l}\text { Ranking } \\
\text { at } R c_{\text {, }} \\
£ 30,00 \\
0\end{array}$ \\
\hline Scottish & $£ 2164$ & $*$ & $10 \cdot 2631$ & $*$ & $*$ & $8 \cdot 7029$ & * & $*$ & 1 \\
\hline English & $£ 2374$ & $£ 210$ & $10 \cdot 2703$ & 0.0072 & $£ 29,170^{d}$ & $8 \cdot 7033$ & 0.0004 & $£ 473,005^{d}$ & 4 \\
\hline Hybrid & $£ 2320$ & $£ 156$ & $10 \cdot 2700$ & 0.0069 & $£ 22,583^{d}$ & $8 \cdot 7033$ & 0.0004 & $£ 353,927^{d}$ & 3 \\
\hline $\begin{array}{l}\text { Automate } \\
d^{a}\end{array}$ & $£ 2277$ & $£ 113$ & $10 \cdot 2709$ & 0.0078 & $£ 14,399$ & $8 \cdot 7034$ & 0.0005 & $£ 222,210$ & 2 \\
\hline $\begin{array}{l}\text { Scottish + } \\
\text { OCT }\end{array}$ & $£ 1814$ & $*$ & $10 \cdot 2631$ & $*$ & $*$ & $8 \cdot 7029$ & $*$ & $*$ & 1 \\
\hline $\begin{array}{l}\text { English + } \\
\text { OCT }\end{array}$ & $£ 1965$ & $£ 151$ & $10 \cdot 2703$ & 0.0072 & $£ 20,975^{d}$ & $8 \cdot 7033$ & 0.0004 & $£ 340,113^{d}$ & 4 \\
\hline
\end{tabular}




\begin{tabular}{|c|c|c|c|c|c|c|c|c|}
\hline $\begin{array}{l}\text { Hybrid + } \\
\text { OCT }\end{array}$ & $£ 1925$ & $£ 111$ & $10 \cdot 2700$ & 0.0069 & $£ 16,069^{d}$ & $8 \cdot 7033$ & 0.0004 & $£ 251,833^{d}$ \\
\hline $\begin{array}{l}\text { Automate } \\
d+\text { OCT }^{a}\end{array}$ & $£ 1894$ & $£ 80$ & $10 \cdot 2709$ & 0.0078 & $£ 10,194$ & $8 \cdot 7034$ & 0.0005 & $£ 157,317$ \\
\hline $\begin{array}{l}\text { Scheme A } \\
+ \text { OCT }\end{array}$ & $£ 2109$ & $£ 295$ & $10 \cdot 2788$ & 0.0157 & $£ 18,832$ & $8 \cdot 7038$ & 0.0009 & $£ 329,497$ \\
\hline
\end{tabular}

OCT optical coherence tomography

* Reference scheme; ${ }^{a}$ figures in table based on assumption that fully automated grading can be implemented at zero net increase in grading costs; ${ }^{d}$ scheme more costly and less effective than an alternative scheme (dominated); Rc, ceiling ratio of willingness to pay per QALY gained 
Figure 4 summarises the probabilistic sensitivity analysis results, showing that Scotland's scheme retains the highest probability of being cost-effective up to a ceiling "willingness to pay" ratio of $\sim £ 240,000$ per QALY when used in conjunction with OCT.

\section{DISCUSSION}

Comparison was made between England's and Scotland's maculopathy grading schemes, along with a hybrid scheme and an automated scheme. In the weighted analysis Scotland achieved a sensitivity of $59.5 \%$ and specificity of 79.0\%. England had a higher sensitivity (72.6\%) but a lower specificity $(66.8 \%)$. Compared to England, the hybrid scheme increased sensitivity by $0.7 \%$ and specificity by $4 \cdot 1 \%$.

Statistical analyses were completed at the patient level. This gave higher sensitivity and lower specificity for each scheme than if using a single eye per patient. However, the order of the performances and costs are unaffected compared to single eye analyses.

Based on weighted data the English and hybrid schemes result in higher numbers of true cases being identified, costing an additional $£ 910$ and $£ 639$ per extra case in the first cycle of the model. However, the repetitive nature of interval screening compromises the cost-effectiveness of schemes that have lower specificity. While the more sensitive schemes gave rise to small increases in years free from moderate visual loss ( $\geq 15$ ETDRS letters), this translated into very small increases in QALYs as such visual losses are associated with a modest utility decrement and may only affect the worst seeing eye. Furthermore, patients missed in one round of screening have a chance of being detected at the next.

While the cost-effectiveness model assumed all patients referred with macular oedema undergo laser treatment, results remained robust when only those patients with macular oedema and visual acuity $\geq 0.3$ logMar were modelled to incur treatment costs. With several parameter values and assumptions weighted in favour of the more sensitive schemes, the additional costs of these schemes (per QALY gained) remained above thresholds for cost-effectiveness.[19] 
With weighted data, automated grading (working at any operating point on its receiver operating characteristic curve) improved performance over the manual schemes. Cost effectiveness will depend on the operating point chosen, the costs of implementation, balanced against cost savings resulting from reductions in manual grading time and unnecessary referrals.[9]

In this study, a variety of OCT scanners were used. A variation in detection of diabetic macular oedema between centres was noted, partly due to differences in the sensitivity of the scanner and partly due to case-selection. Cases missed by less sensitive scanners may have biased the estimated sensitivities and specificities, but most likely in the same directions for all schemes. Hence they are unlikely to have affected the broader inferences.

Economic modelling suggests that the use of OCT in conjunction with photography within screening programmes, for patients with surrogate markers of oedema, is likely to be cost-effective. The estimated marginal cost of conducting OCT within the screening programme (£32) is low in comparison with the cost of referral to ophthalmology $(£ 143)$ and consequent monitoring in the outpatient setting. As the analysis included a survey of costs and pathways of implementation in the participating centres the results can be applied across England and Scotland.

We assumed that patients without treatment would progress at the rate observed in the Early Treatment Diabetic Retinopathy Study.[14] To assess the benefits of improved detection and referral, the best available evidence was used.[4,14,15] Although Ranibizumab has now been approved,[21] its impact on the cost-effectiveness of screening for macular oedema is unknown.

Considering the comparison of alternative photographic grading schemes in England and Scotland for triggering referral to ophthalmology or an OCT examination, we found Scotland's scheme to be preferred based on weighted data when applying a ceiling ratio of $£ 30,000$ per QALY gained.

Automated grading benefits from the ability to choose different operating points, depending on the sensitivity desired. At the study's chosen operating point, if it could be implemented without increasing grading costs, automation could produce a similar number of QALYS for a lower overall cost than England's 
scheme. Automated grading could be made cost-effective in Scotland, but an operating point at a higher specificity would have to be chosen.

Utilising optical coherence tomography, as part of the screening pathway, could reduce costs to the health service.

Retinal screening programmes in the United Kingdom should reconsider the screening pathway to make best use of existing and new technologies. 
Acknowledgements

This project could not have been successfully completed without the cooperation of all the centres. Much of the workload of acquiring the data was carried out by the retinal screeners, supported by the clinical staff. Our particular thanks go to Julie Raeper, a Senior Retinal Screener at Aberdeen Royal Infirmary, who manually graded and annotated all the images.

Thanks must go to those who sat on the Trials Steering Committee and the Investigators' Meetings. In particular those members not involved directly in the study; Mr Stephen Graham, our patient representative, Prof Alex Elliott, Dr Ayyakkannu Manivannan and Mrs Alison Farrow. Thanks also for the guidance of the chair of the Trials Steering Committee, initially, Dr Caroline Styles and later Dr Rod Harvey.

\section{Competing interests}

John Olson, Gordon Prescott, Peter Sharp, Sam Phillip and Alan Fleming have received funding for their institution from the Chief Scientist Office, Scotland and from Medalytix Ltd. Alan Fleming has received salary support from Medalytix Ltd. Simon Harding has received conference funding from Allergan. Ken Swa sits on the Novartis Advisory Board (Scotland). Commercial implementation associated with some of the referenced work may in future provide some remuneration for the University of Aberdeen, NHS Grampian and Aberdeen based authors.

Funding

Funding for this study was provided by the Health Technology Assessment programme of the National Institute for Health Research, project reference 06/402/49.

Authors' contributions statement

JAO was the principal investigator. JAO, PFS, KAG, SP, ADF, GSS, PMD, GJP, SB, DMB, VC, SPH, GPL, CJS, KS, and HMW contributed to the study design. KAG managed the data collection. The web-based grading database was developed by KAG and ADF. CSa, SB, DMB, VC, PMD, SPH, GPL, CJS, RDM, KS and HMW were responsible for providing patient data from the collaborating centres. KAG and ADF developed the automated analysis and with RTS generated the results. JAO 
performed quality assurance. GJP, KAG, ADF performed the statistical analyses and GJP checked the validity of the statistical analyses. GSS performed all of the economic analyses. GJP and ADF wrote the first draft of the paper. All authors participated in the interpretation of the data, reviewed and revised the paper for important intellectual content and approved the final version. JAO takes responsibility for the content. 


\section{References}

1. HTA. Can automated diabetic retinopathy image assessment software replace one or more steps of manual imaging grading and is this costeffective for the NHS Diabetic Eye Screening Programme? Available at: http://www.hta.ac.uk/2923 (Accessed 21 April 2013).

2. Goatman KA. A reference standard for the measurement of macular oedema. Br J Ophthalmol 2006;90:1197-202.

3. Massin P, Girach A, Erginay A, et al. Optical coherence tomography: a key to the future management of patients with diabetic macular oedema. Acta Ophthalmol Scand 2006;84:466-74.

4. Early photocoagulation for diabetic retinopathy. ETDRS report number 9. Early Treatment Diabetic Retinopathy Study Research Group. Ophthalmology 1991;98(Suppl):766-85.

5. Goatman KA, Philip S, Fleming AD, et al. External quality assurance for image grading in the Scottish Diabetic Retinopathy Screening Programme. Diabet Med 2012;29:776-83.

6. Fleming AD, Goatman KA, Philip $S$, et al. on behalf of the Scottish Diabetic Retinopathy Clinical Research Network. The role of haemorrhage and exudate detection in automated grading of diabetic retinopathy. $\mathrm{Br} \mathrm{J}$ Ophthalmol 2010;94:706-11.

7. Scotland GS, McNamee P, Fleming AD, et al. on behalf of the Scottish Diabetic Retinopathy Clinical Research Network. Costs and consequences of automated algorithms versus manual grading for the detection of referable diabetic retinopathy. $\mathrm{Br} J$ Ophthalmol 2010;94:712-719. 
8. Kish L. Survey sampling. New York: Wiley 1965:424-6.

9. Philip S, Fleming AD, Goatman KA, et al. The efficacy of automated "disease/no disease" grading for diabetic retinopathy in a systematic screening programme. Br J Ophthalmol 2007;91:1512-7.

10. Bethlehem J. Weighting. In: Lavrakas PJ, editor. The encyclopedia of survey research methods. Volume 2. New York: Sage 2008:957-60.

11. Sapsford R. Survey research. London: Sage 1999:31-2.

12. Warwick D, Lininger CA. The sample survey: theory and practice. New York: McGraw-Hill 1975:273-4.

13. Altman DG, Machin D, Bryant TN, Gardner MJ. Statistics with Confidence. London: BMJ Books 2000:46-8.

14. Early Treatment for Diabetic Retinopathy Study. Photocoagulation for Diabetic Macular Edema. Early Treatment Diabetic Retinopathy Study report number 1. Early Treatment Diabetic Retinopathy Study research group. Arch Ophthalmol 1985;103:1796-806.

15. Jyothi S, Sivaprasad S. Five-year visual outcome following laser photocoagulation of diabetic macular oedema. Eye 2011;25:850-9.

16. Department of Health 2010; NHS reference costs 2009-2010. Available from: https://www.gov.uk/government/publications/nhs-reference-costs2009-2010 (Accessed 21 April 2013).

17. PSSRU. Unit Costs of Health and Social Care 2010. Canterbury: Personal Social Services Research Unit, University of Kent 2010. 
18. Meads C, Hyde C. What is the cost of blindness? $\mathrm{Br} \mathrm{J}$ Ophthalmol $2003 ; 87: 1201-4$.

19. McCabe C, Claxton K, Culyer AJ. The NICE cost-effectiveness threshold: what it is and what that means. Pharmacoeconomics 2008;26:733-44.

20. Briggs A, Claxton C, Sculpher M. Decision modelling for health economic evaluation. Oxford University Press: Oxford 2007:121-63.

21. National Institute for Health and Clinical Excellence. Ranibizumab for treating diabetic macular oedema (rapid review of technology appraisal guidance 237) National Institute for Health and Clinical Excellence site. Available at: http://www.nice.org.uk/nicemedia/live/14082/62873/62873.pdf. (Accessed 21 April 2013). 
Figure legends:

FIGURE 1 Study design for recruitment, with hybrid manual grading scheme as the diagnostic test and with the reference standard of macular oedema presence. "Positive" means that the image was judged to have macular oedema.

FIGURE 2 Study design for recruitment, with automated image analysis as the diagnostic test and with the reference standard of macular oedema presence. "Positive" means that the image was judged to have macular oedema.

FIGURE 3 Unweighted a) and weighted b) receiver operating characteristics curves for fully automated annotation grading including the operating point chosen. The performances of the manual schemes associated with current United Kingdom grading practice (England and Scotland), and of the manual grading schemes used in the economic analysis (hybrid manual) are also shown.

FIGURE 4 Cost-effectiveness acceptability curves for the alternative grading schemes when used a) without OCT and b) with OCT prior to referral - based on a 20 year time horizon and using quality adjusted life years as the measure of outcome. 